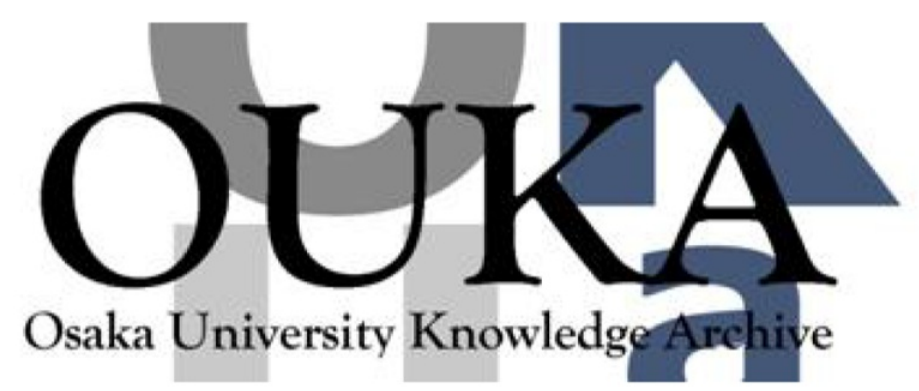

\begin{tabular}{|c|l|}
\hline Title & $\begin{array}{l}\text { Stored Energy Welding Technology of Ultra-thin } \\
\text { Sheet Stainless Steel }\end{array}$ \\
\hline Author(s) & Wang, Xiaowei; Zhou, Haobin; Xu, Xiangqian \\
\hline Citation & Transactions of JWRI. WSE2011 p.31-p. 32 \\
\hline Issue Date & $2012-03$ \\
\hline oaire:version & VoR \\
\hline URL & https://doi.org/10.18910/23078 \\
\hline rights & \\
\hline Note & \\
\hline
\end{tabular}

Osaka University Knowledge Archive : OUKA

https://ir. Library. osaka-u. ac. jp/

Osaka University 


\title{
Stored Energy Welding Technology of Ultra-thin Sheet Stainless Steel
}

\author{
Xiaowei WANG, Haobin ZHOU and Xiangqian XU \\ (School of Material Science and Engineering, Xi'an Shiyou University, Xi'an 710065, China)
}

Key words: Ultra-thin sheet stainless steel; Condenser discharge spot welding; Methods of quality assessment.

In the spot welding for different superimposed layers of $0.1 \mathrm{~mm}$ ultra-thin Sheet 304 stainless steel, it causes the workpiece burning through or welding fail easily because of the traditional energy storage welding standard are often "higher". The spot welding parameters are not easy to control, most especially for the thickness about $0.1 \mathrm{~mm}$. It is difficult to meet the quality of expected welding.

Condenser discharge spot welding is widely used in precision spot welding because of its characteristics of current waveform easy to control and energy concentration for condenser discharge. The feasibility of welding ultra-thin stainless steel sheet through Condenser discharge is investigated by this paper. In order to overcome the disadvantages of traditional energy storage welding machine, we have designed a dedicated welder that applies to weld 0.1 $\mathrm{mm}$ ultra-thin Sheet 304 stainless steel. Because there is no unified standard for solder joints of quality evaluation of ultra-thin stainless steel within the thickness of $0.3 \mathrm{~mm}$, this paper has also solved the problem of how to establish the assessment methods of solder joints quality for ultra-thin material.

\section{Technology and experiment scheme \\ 1.1 Experiment principle and procedure}

During the condenser discharge spot welding, the process of energy transfer abides the equation below:

$$
\eta \bullet \frac{1}{2} C_{P} U_{c}^{2}=I^{2} R t=E_{1}+E_{2}
$$

Where $C_{P}$ represents capacity $(F), \eta$ means capacitance discharge efficiency; $U_{C}$ represents capacitance charging voltage(V); I represents current strength(A); R represents total resistance of welding area; $t$ represents pulse time of welding current; $\mathrm{E}_{1}$ represents the energy used to heat the workpiece to the welding temperature; $\mathrm{E}_{2}$ represents the lost energy of workpiece and welding loop.

From the equation above, two ways to improve welding energy in practical welding can be concluded: enhance $C_{P}$ while keep $U_{C}$ stable because $R$ is fixed, or enhance $U_{C}$ while keep $C_{P}$ stable. The method that regulate the capacity to adjust welding energy by putting capacities in parallel is put forward in this experiment in consideration of precision of energy controlling, because of the index amplification of $\mathrm{U}_{\mathrm{C}}$ and thickness of ultra-thin materials: $0.01 \mathrm{~mm}$. This can settle the problem that welding standard is too "high" to burning through the ultra-thin stainless steels, and putting the capacities in parallel enhances the stableness of discharging.

Fig. 1 shows the principle of welding machine, which is designed for the $0.01 \mathrm{~mm}$ ultra-thin steels specially. Its capacitance group is charged by $220 \mathrm{~V}$ AC power source through Rectifier Bridge. Charging-discharging of the capacitance group, regulation of pressurized structure and display of parameter of welding are achieved by the controlling part in the welding loop. This welding machine overcomes the shortage of normal machines with "higher" welding standard. In this experiment, the best suitable welding parameters are got by controlling the energy of capacitance group and suitable electrode pressure.

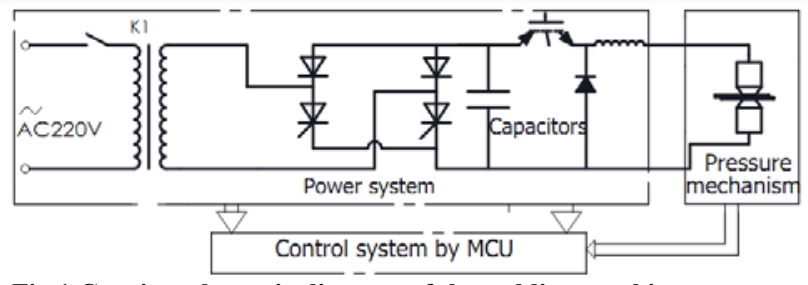

Fig.1 Concise schematic diagram of the welding machine

The dimension of the sample board that the material is 304 stainless steel $(0 \mathrm{Cr} 18 \mathrm{Ni} 9)$ is $40 \mathrm{~mm} \times 10 \mathrm{~mm} \times 0.1 \mathrm{~mm}$. The test procedure is as follows: firstly, the single spot welding that the welding energy and electrode force are in a selected range is done from nonwelding to burning through on 3 layers. The single spot welding is done on every five workpieces in the same welding parameters. (Every five workpieces is a group, each group must have one simple tearingtest. And ensure that there are no joint defects on this welded plate, otherwise this plate must be canceled) The plate-sheartest is after that. Then calculate the average value of each five plate-sheartest workpieces in order to get the best welding parameters; and then the defects can be analysised by Metallographic examination which derive from workpieces that have the Max shear stress. Then the best welding parameters of 3 layers can be got by the plate-sheartest and metallographic examination.

During the execution of experiments some points should be paid attention to as follow:

(1) The thicker the copper cable is the better for welding circuit. For that can decrease the resistance of spot welding discharge circuit; Checking the welding circuit is correct before the main switch is opened; And the welding electrode should be keep smooth and flat.

(2)Before welding the water, the rust, the grease as well as the other impurities must be cleared up on the surface of workpieces, then use industrial alcohol to wipe the surface.

(3) Check the welding electrode .If the electrode has oxidation or damage, repair it.

\subsection{The assessment methods of solder joint quality}

1.2.1 The assessment methods

Because there is no unified standard that is in the traditional assessment methods for solder joints of quality evaluation of ultra-thin stainless steel within the thickness of 


\section{Stored Energy Welding Technology of Ultra-thin Sheet Stainless Steel}

$0.3 \mathrm{~mm}$. Based on principle of the reference [1] and [2], this paper set a new assessment method which includes Tearingtest, Plate-sheartest and Metallographic examination.

Tearingtest that the welded workpieces are stripped and twisted can get the sketchy performance of the workpieces. This test must be finished before the Plate-sheartest, which is useful to select the suitable unwelded workpieces.

Mechanic property of the welding spot is got from plate-sheartest, which is an effective guarantee for the practical application of finished products. The increasing speed of shearing force is $50 \mathrm{~N} / \mathrm{s}$.

Lastly, The welded joint defects that include crackle, gas hole, inclusion and so on can be analysised by Metallographic examination that is made from crosssectoin of the welded workpieces.

\subsubsection{Geometry and dimension of the workpieces}

The dimensions of the sample board and its base plate can be see in Fig.2. The base plates that are used in each test are added (see the hatch areas in Fig.2) in case that axis of load drift away from the centerline.

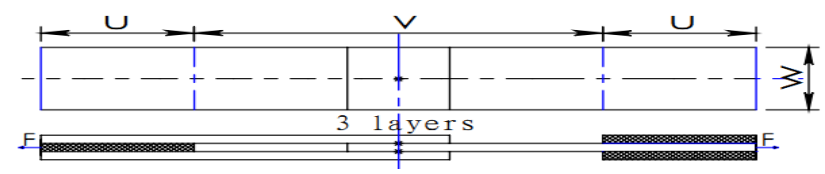

Fig.2 The Dimensions of the sample board and its base plate

The experiment can start by the test procedure and notice, and then draw the diagrams that illustrate the relation between the welding energy $(\mathrm{Q})$ and shear stress $(\mathrm{F})$.

\section{Experimental results and analysis}

2.1 The influences of the welding press to the quality of spot welding workpieces

The electrode force which is too low to weld easily or serious sputter, and too high, which cause overlarge plastic deformation to the material whose thickness is $0.1 \mathrm{~mm}$ only. These conditions have a great influence to the quality of welding, so the reasonable value should be chosen to the electrode force. If the premise of overlarge plastic deformation and serious sputter of the workpieces is avoided, it is chosen that the welding energy which is $70 \mathrm{~J}$ for 3 layers. The best electrode force is chosen by different electrode force. This paper excludes the interaction of orthogonal activities between welding energy and electrode force to the quality of spot welding workpiece. Considering the good appearance and the magnitude of plate-sheartest (see Tab.1), The best electrode force has been elected.

\subsection{The influences of the welding energy to the quality of spot welding workpieces} welding press

Tab.1 The experimental data of spot welding sample at different

\begin{tabular}{|l|l|l|l|l|}
\hline electrode force $(\mathrm{N})$ & 200 & 250 & 300 & 350 \\
\hline shear stress $(\mathrm{N})$ & 308 & 310 & 302 & 292 \\
\hline
\end{tabular}

Using the respective best electrode force above, series welding energies were chosen to do the welding tests; the results are shown in figure 2 . It can be seen that the welding energy has a great influence to shear stress. In a certain range, the shear stress becomes higher with increasing welding energy, however when the welding energy increase to a certain degree, it will cause burning through. Although shear force has increased, the welding spatter increased seriously when welding energy higher than $96 \mathrm{~J}$. it is most likely to cause oxidation or damage to the electrode. Considering service life of the electrode and good solder joint appearance, Hence 3 layers was selected $96 \mathrm{~J}$ as its own best welding energy.

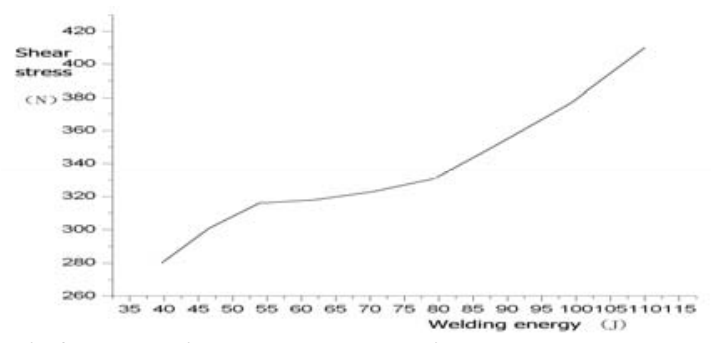

Fig. 3 The relation between the welding energy and shear stress

\subsection{Metallographic examination}

As is shown in Fig.4 that the welding parameters. These metallographs indicate that these welding spots have no air hole and crackle. And it will be more reliable guarantee for the engineering practice using of the solder joints.

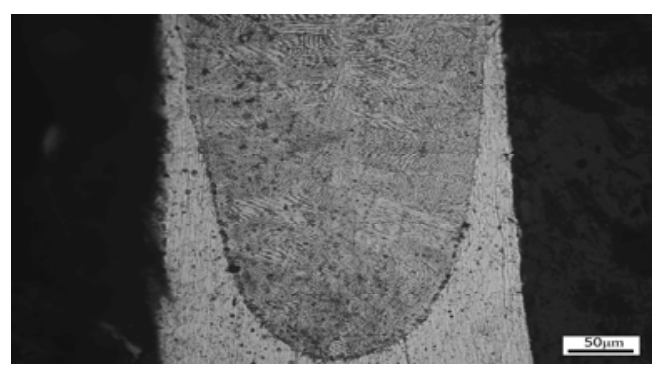

Fig.4 the metallographs of welding spot for superimposed layers

\section{Conclusions}

1) The reasonable value should be chosen for the electrode force.

2) The appropriate welding energy should be kept.

\section{References}

[1] HB 5282-1984 Quality Examination of Resistance Spot Welding on Seam Welding Structural and Steel Stainless Steel [S].

[2] GB/T 15111-1994 Test Methods of Shearing, Pulling and Fatigue on Spot-welded Joints [S].

[3] Xihua Zhao, Jicai Feng. Technology and Equipment of Pressure Welding [M].Beijing China Machine Press, 2005. 